\title{
Olfactory Neuroblastoma Causing Ectopic ACTH Syndrome
}

\author{
KAZUO KANNO, YUKI MOROKUMA***, TORU TATENO***, YUKI HIRONO***, KAZUHIRO TAKI*, \\ R. YOSHIYUKI OSAMURA** AND YUKIO HIRATA*** \\ Division of Endocrinology and Metabolism, Musashino Red Cross Hospital, Tokyo 180-8610, Japan \\ *Division of Pathology, Musashino Red Cross Hospital, Tokyo 180-8610, Japan \\ **Department of Pathology, Tokai University School of Medicine, Isehara 259-1193, Japan \\ ***Department of Clinical and Molecular Endocrinology, Tokyo Medical and Dental University Graduate School, Tokyo 113-8519, Japan
}

\begin{abstract}
A 39-year-old woman who presented with typical Cushingoid appearance (moon facies, central obesity, purpura) was admitted to our hospital because of pulmonary infection. She was found to have hypertension, severe hypokalemia, and metabolic alkalosis. Endocrine data revealed elevated plasma levels of ACTH and cortisol with lack of circadian rhythm, non-suppressibility to high-dose dexamethasone, and hyperresponsiveness to CRH stimulation. Although no pituitary mass was detected by MRI of the brain, inferior petrosal sinus sampling showed a step-up of central to peripheral ACTH levels; these data are consistent with the diagnosis of Cushing's disease. She was successfully treated with metyrapone to control hypercortisolemia. Ten months later, a mass was detected in the ethmoid sinus, which was surgically removed. After resection of the ethmoid sinus tumor, her Cushingoid features and hypercortisolemia disappeared, but recurred after enlargement of a second mass in the maxillary sinus. After resection of the maxillary sinus tumor, her hypercortisolemia subsided. Histologically, the tumor tissues from both the ethmoid and maxillary sinus were identical and consistent with the diagnosis of olfactory neuroblastoma. Immunohistochemically, the immunoreactivities of ACTH and POMC were positive in the cytoplasm of tumor cells, and immunoreactive ACTH was demonstrated in both tumor tissues. Thus, this is the second rare case with ectopic ACTH syndrome caused by olfactory neuroblastoma thus far reported.
\end{abstract}

Key words: Ectopic ACTH syndrome, Cushing's syndrome, Olfactory neuroblastoma

(Endocrine Journal 52: 675-681, 2005)

AMONG the forms of Cushing's syndrome, Cushing's disease (mostly pituitary ACTH-secreting microadenomas) accounts for $55-82 \%$, while ectopic ACTH syndrome caused by non-pituitary ACTH-secreting tumors occupies about 9-18\% [1]. Most cases of ectopic ACTH-producing tumors have been shown to be malignant neoplasm caused not only by small cell lung carcinoma and bronchial carcinoid, but also by miscellaneous tumors including medullary thyroid carcinoma, pheochromocytoma, carcinoma of thymus and pancreas. Ectopic ACTH syndrome often presents a major diagnostic challenge because of the difficulty in

Received: May 11, 2005

Accepted: August 17, 2005

Correspondence to: Yukio HIRATA, M.D., Department of Clinical and Molecular Endocrinology, Tokyo Medical and Dental University Graduate School, 1-5-45 Yushima, Bunkyo-ku Tokyo, 113-8519 Japan differentiating it from Cushing's disease [2,3]. Moreover, localization of ACTH-secreting tumors by the diagnostic image tests is often difficult; magnetic resonance image (MRI) of the brain could detect pituitary tumor in only about $40-50 \%$ of the cases in Cushing's disease, while localization of occult and indolent nonpituitary tumors, such as bronchial carcinoid, is often difficult by the current image tests [2,3].

Olfactory neuroblastoma is an uncommon malignant neoplasm with an average 5-year survival rate of about $45 \%$ [4]. Ectopic ACTH syndrome due to olfactory neuroblastoma is extremely rare. There has been only one case of ectopic ACTH-producing olfactory neuroblastoma thus far reported [5]. We herein present a patient with typical Cushing's syndrome due to ectopic ACTH-producing olfactory neuroblastoma, who now survives for 7 years after successful treatment with combination therapy consisting of surgery, radiation and hormonal control. 


\section{Methods and Patient}

\section{ACTH measurement}

Plasma and tissue ACTH concentrations were determined by immunoradiometric assay (IRMA) using Yuka ACTH IRMA kit (Mitsubishi Yuka, Tokyo, Japan) which showed full crossreactivity with ACTH (1-39), but none with ACTH fragments (1-13), (1-24), (11-24), (18-39), $\beta$-lipotropin or $\beta$-endorphin [6].

\section{Tumor extraction}

Tumor tissue specimens obtained from surgery were boiled in distilled water, homogenized in a glass-teflon homogenizer, and centrifuged [6]. The supernatant was subjected to ACTH measurement by IRMA.

\section{Immunohistochemical study}

The expression of ACTH and POMC was studied by immunohistochemical Envision method (DAKO, Carpinteria, CA) according to the manufacturer's instructions. Antibodies against ACTH and POMC used in this study were as follows: anti-ACTH monoclonal antibody (DAKO) used at dilution $1: 200$, and anti-POMC monoclonal antibody (Biogenesis, Poole, UK) used at $1: 400$. Positive immunoreactions were visualized by $3-3$ ' diaminobenzidine reaction of horseradish peroxidase as reported [7].

\section{Case Report}

A 39-year-old Japanese woman was admitted to our hospital because of systemic edema and general fatigue in October, 1997. Physical examination showed a typical Cushingoid appearance (moon facies, truncal obesity), systemic edema, purpura and high blood pressure $(166 / 80 \mathrm{mmHg})$. Laboratory examination revealed a profound hypokalemia $(1.2 \mathrm{mEq} / \mathrm{l})$ and metabolic alkalosis (pH 7.63, $\left.\mathrm{HCO}_{3}{ }^{-} 50.4 \mathrm{mmol} / \mathrm{l}\right)$. Endocrine test revealed a marked elevation of plasma ACTH $(150 \mathrm{pg} /$ $\mathrm{ml})$ and cortisol levels $(80.1 \mu \mathrm{g} / \mathrm{dl})$, which lacked normal circadian rhythm, and were non-suppressibile to high-dose $(8 \mathrm{mg})$ dexamethasone and hyperresponsive to $\mathrm{CRH}$ stimulation (Table 1). These physical and endocrine findings are consistent with the diagnosis of ACTH-dependent Cushing's syndrome.
Table 1. Endocrine Data

\begin{tabular}{lccc}
\hline 1. Circadian rhythm & & & \\
\hline Time (clock) & $9: 00$ & $16: 00$ & $23: 00$ \\
\hline ACTH $(\mathrm{pg} / \mathrm{ml})$ & 150 & 140 & 350 \\
Cortisol $(\mu \mathrm{g} / \mathrm{dl})$ & 80.3 & 52.3 & 78.1 \\
\hline
\end{tabular}

2. DEX* suppression test

\begin{tabular}{lc}
\hline Time $($ clock $)$ & $9: 00$ \\
\hline ACTH $(\mathrm{pg} / \mathrm{ml})$ & 180 \\
Cortisol $(\mu \mathrm{g} / \mathrm{dl})$ & 65.5 \\
\hline
\end{tabular}

\begin{tabular}{|c|c|c|c|c|c|}
\hline Time (min) & 0 & 30 & 60 & 90 & 120 \\
\hline ACTH (pg/ml) & 120 & 1800 & 730 & 520 & 340 \\
\hline Cortisol $(\mu \mathrm{g} / \mathrm{dl})$ & 43.7 & 82.7 & 87.4 & 101.2 & 93.6 \\
\hline
\end{tabular}

* DEX: dexamethasone $(8 \mathrm{mg}$ ) was given orally at 23:00 the day before.

On admission, she had fever $\left(38.5^{\circ} \mathrm{C}\right)$ with leukocytosis and positive C-reactive protein; X-ray and computed tomography (CT) scan of the chest revealed pulmonary empyema. She was immediately treated with antibiotics for sepsis and metyrapone to reduce plasma cortisol levels, and underwent chest drainage; her condition improved after two weeks. CT scan of the chest revealed a nodular lesion in the right lung (S5), whose lung biopsy only revealed inflammatory fibrotic changes. To differentiate Cushing's disease from ectopic ACTH syndrome, inferior petrosal sinus (IPS) sampling was performed. Plasma ACTH levels in the right and the left IPS and peripheral vein were 58,130 , and $47 \mathrm{pg} / \mathrm{ml}$, respectively, with a central/ peripheral $(\mathrm{C} / \mathrm{P})$ ratio of 2.8 ; $\mathrm{CRH}$ stimulation was not performed. Thus, Cushing's disease was the most likely diagnosis, although MRI of the brain failed to identify any pituitary lesions. She was treated with metyrapone (1.5-2.0 g/day) and dexamethasone (1 $\mathrm{mg} /$ day); her plasma ACTH and cortisol levels were 58 $\mathrm{pg} / \mathrm{ml}$ and $3.7 \mu \mathrm{g} / \mathrm{dl}$, respectively (Fig. 1). Her signs and symptoms associated with Cushing's syndrome improved remarkably and she was discharged.

In September 1998, repeated MRI of the brain incidentally revealed a large tumor $(2.5 \times 3.0 \mathrm{~cm})$ in ethmoid sinus (Fig. 2a). The tumor was surgically and completely resected 16 months after she developed Cushing's syndrome (Fig. 2b, c). Histologically, the ethmoid tumor was composed of small round cells with uniform round nuclei consistent with the diag- 


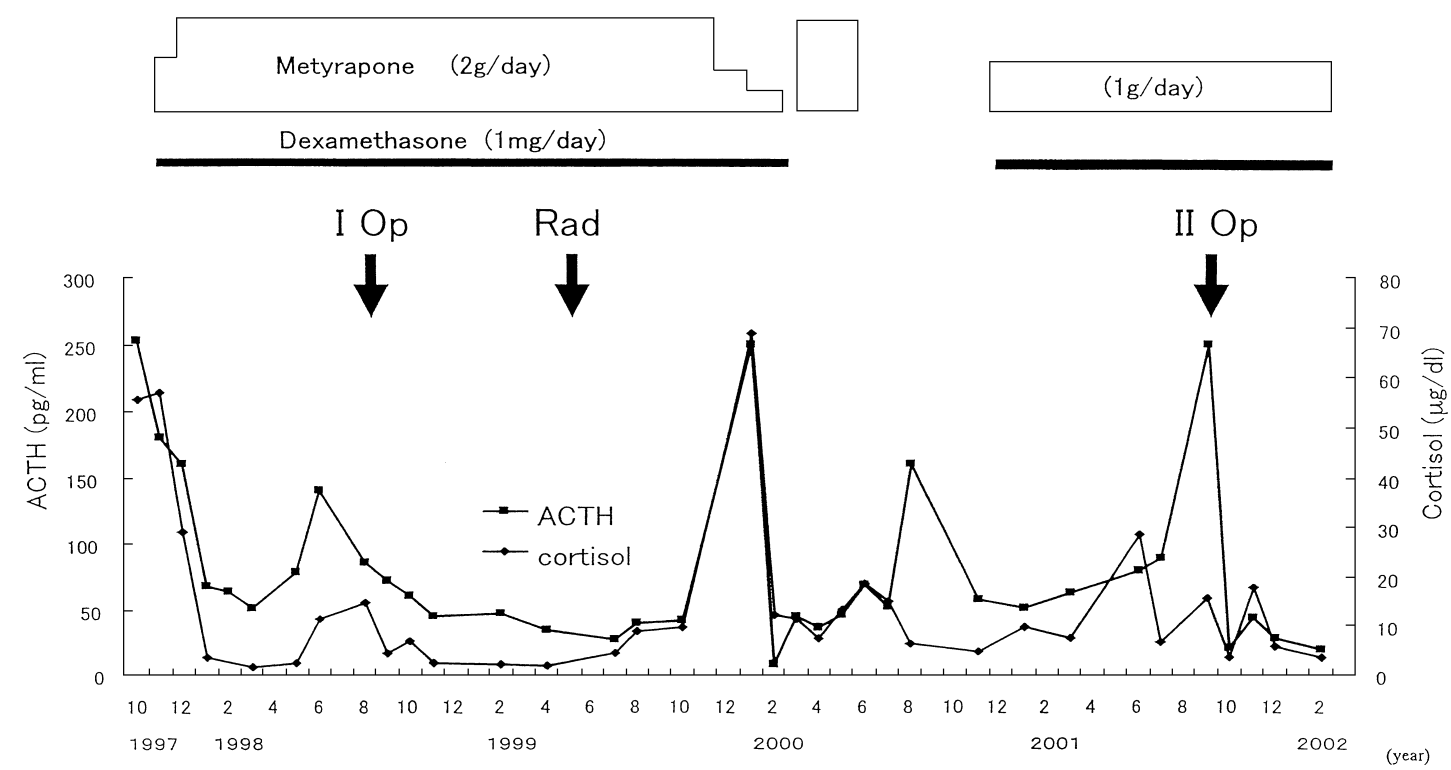

Fig. 1. Changes of plasma ACTH and cortisol levels during clinical course

$\operatorname{ACTH}(\boldsymbol{\square})$, Cortisol $(\diamond)$. Medical treatment is shown at the top; operations (Op) and rdiation (Rad) are shown by arrows.

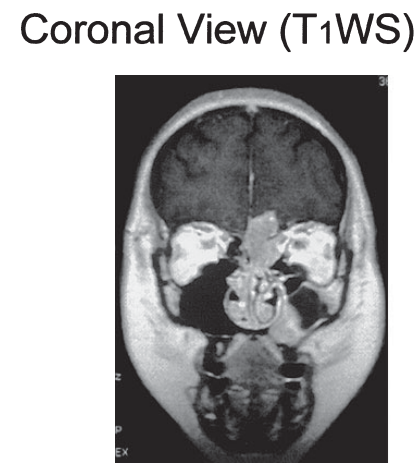

a

\section{Sagittal View (T1WS)}

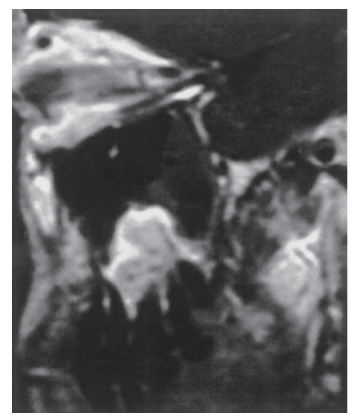

$\mathbf{a}$

$(9 / 98)$

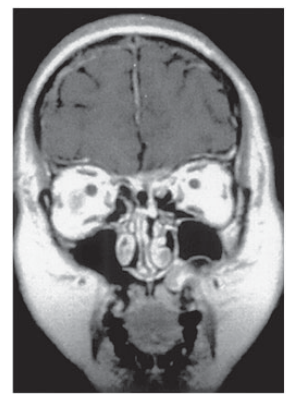

b

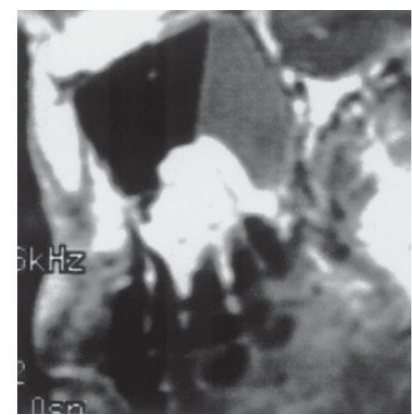

b

$(11 / 299)$

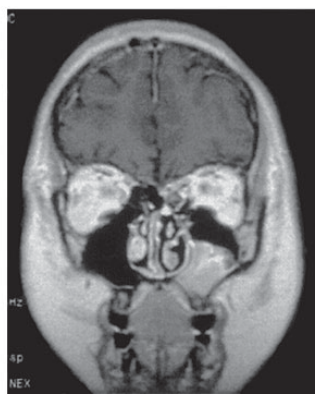

c

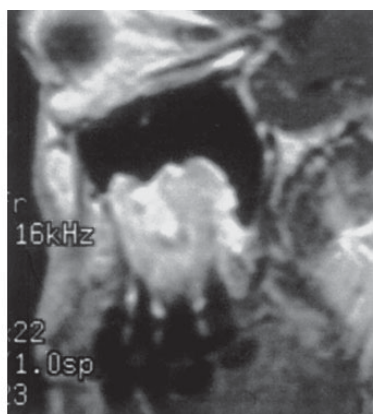

c

$\left(8 /{ }^{\prime} 01\right)$

Fig. 2. Magnetic resonance image (MRI) of the head

Sequential coronal views (top) and sagittal views (bottom) of MRI of the head are shown (a) before and (b) after the first operation, and (c) after the second operation. 

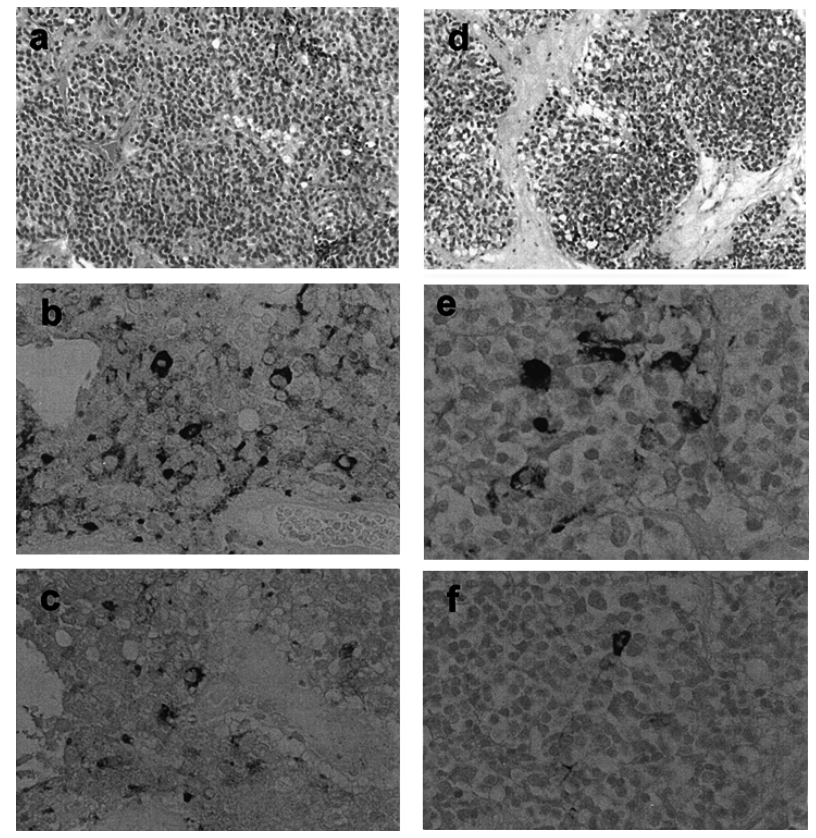

Fig. 3. Histopathological study of ethmoid and maxillary sinus tumor tissues

Microscopical and immunocytochemical examinations of ethmoid sinus tumor (left) and maxillary sinus tumor (right) are shown.

(a, d) H \& E $(\times 100)$; (b, e) immunostaining for ACTH $(\times 200),(c, f)$ immunostaining for POMC $(\times 200)$

nosis of olfactory neuroblastoma (Fig. 3a). Immunohistochemical study revealed abundant immunoreactive ACTH- and POMC-positive tumor cells (Fig. 3b, c). The ACTH content of the resected tumor tissue as determined by IRMA was $648 \mu \mathrm{g} / \mathrm{mg}$ protein. Thus, the definitive diagnosis of ACTH-producing olfactory neuroblastoma was established. Postoperatively, her plasma ACTH and cortisol levels decreased from 150 to $60 \mathrm{pg} / \mathrm{ml}$ and from 14 to $6.7 \mu \mathrm{g} / \mathrm{dl}$, respectively (Fig. 1).

In June 1999, she received local irradiation directed to the ethmoid sinus area (total dose: 54 Gy). Since her Cushingoid appearance completely disappeared, metyrapone was discontinued in August 1999. However, her plasma ACTH and cortisol levels began to increase, which made her to receive again metyrapone ( $2 \mathrm{~g} /$ day) in August 2000.

In July 2001, systemic edema and general fatigue again developed with increased plasma levels of ACTH $(250 \mathrm{pg} / \mathrm{ml})$ and cortisol $(15.3 \mu \mathrm{g} / \mathrm{dl})$, despite metyrapone administration, which led her to be readmitted to our hospital. Although CT scan and MRI of the brain showed a second mass lesion $(3.0 \times 2.0 \mathrm{~cm})$ in the left maxillary sinus in September 1998 (Fig. 2a), it was considered as an inflammatory change associated with chronic sinusitis. However, CT scan and MRI of the brain revealed an increased size $(4.2 \times 2.8 \mathrm{~cm})$ in the left maxillary sinus mass (Fig. 2b). Because of the possible metastasis of ethmoid sinus tumor to maxillary sinus, the tumor of the maxillary sinus was surgically resected (Fig. 2c). The tumor was composed of round, chromatin-rich tumor cells with the same histological characteristics as those of the ethmoid sinus tumor, which was consistent with the diagnosis of olfactory neuroblastoma (Fig. 3d). Immunohistochemical study also revealed immunoreactive ACTH-positive and POMC-positive tumor cells (Fig. 3e, f), but apparently fewer than those in the ethmoid sinus tumor. The ACTH content of the resected tumor tissue was $5 \mathrm{ng} / \mathrm{mg}$ protein. After removal of the maxillary sinus tumor, her Cushingoid signs and symptoms resolved completely and her plasma ACTH and cortisol levels remarkably decreased to $20 \mathrm{pg} / \mathrm{ml}$ and $3.5 \mu \mathrm{g} / \mathrm{dl}$, respectively. Thereafter, she is doing well without metyrapone treatment. She is currently followed-up at outpatient department without recurrence of Cushing's syndrome.

\section{Discussion}

The patient described herein presented with typical Cushingoid appearance together with hypertension, severe hypokalemia, and increased plasma ACTH and cortisol levels, which are consistent with the diagnosis of ACTH-dependent Cushing's syndrome. The endocrine data with hyperresponsiveness of ACTH after CRH stimulation and a step-up of plasma ACTH levels in IPS, are compatible with the diagnosis of Cushing's disease, although she showed resistance to high-dose dexamethasone suppression and no detectable pituitary tumor with MRI of the brain. Since she was under such an immunocompromised state due to hypercortisolemia that immediate medical treatment was started; her hypercortisolemia was well controlled with combination of metyrapone and dexamethasone. Subsequently, two mass lesions were incidentally detected initially in the ethmoid sinus and later in the maxillary sinus by MRI of the brain, both of which were sequentially resected surgically. Both tumor tissue specimens were histologically identical and consistent with the 
pathological diagnosis of olfactory neuroblastoma.

The diagnosis of ectopic ACTH syndrome in this case was definitely established based on the following lines of evidence: 1) the presence of abundant ACTH content in ethmoid sinus tumor $(648 \mu \mathrm{g} / \mathrm{mg}$ protein $)$ and maxillary sinus tumor (5 $\mathrm{ng} / \mathrm{mg}$ protein); 2 ) immunohistochemical demonstration of ACTH and POMC immunoreactivities in both tumor cells; 3 ) disappearance of Cushingoid features accompanied by decrease in plasma ACTH and cortisol levels after resection of ethmoid sinus tumor; 4) recurrence of Cushing's syndrome accompanied by increase in plasma ACTH and cortisol levels after metastatic tumor growth in the maxillary sinus, whose removal again led to amelioration of Cushing's syndrome.

Olfactory neuroblastoma is a very uncommon neoplasm of neuroectodermal origin [8,9]; about 1000 cases have been reported thus far [10]. As for the ectopic hormone production by olfactory neuroblastoma, three cases with syndromes of inappropriate secretion of antidiuretic hormone have been reported [11-13]. Although four cases of ectopic ACTH-producing adrenal neuroblastoma were reported in infants [14-17], only one case with ectopic ACTH-producing olfactory neuroblastoma in adulthood has been reported thus far [5]. Thus, our case adds to the literature a second rare case report of ectopic ACTH-producing olfactory neuroblastoma.

The most common symptoms of olfactory neuroblastoma include unilateral nasal congestion, obstruction, anosmia, recurrent epitaxis, frontal headache and diplopia [4]. In our case, none of these symptoms were noted, but signs and symptoms of Cushing's syndrome initially appeared, whose clinical manifestations are similar to those as in the first case reported by Arnesen et al. [5]. The clinical courses of ectopic ACTHproducing olfactory neuroblastoma in these two cases are very similar with regard to the acute onset of the disease, improvement of signs and symptoms of Cushing's syndrome after the first tumor resection, and aggravation of the clinical manifestation after the tumor recurrence. Olfactory neuroblastoma is malignant with an average 5-year survival rate of $45-70 \%$ [4]. The most frequent therapeutic option is combination of surgery and radiotherapy. By employing the combination of repeated tumor resctions and irradiation with adjunctive medical treatment with metyrapone to control hypercortisolemia, our patient managed to survive 7 years since the initial diagnosis of olfactory neuro- blastoma, while Arnesen's case survived at least 5 years [5]. Therefore, the prognosis of ACTH-producing olfactory neuroblastoma seems better than those without ACTH production, possibly due to the early diagnosis resulting from excess hormonal manifestations and the proper therapeutic modality for tumor and hormonal control. However, it has been reported that recurrence occurred even ten years after the completion of treatment [18-20]. Therefore, a close and cautious followup in the present case is needed and implementation of early resection of the recurrent tumor should be made.

Maxillary sinus tumor in the present case was considered metastasis from ethmoid sinus olfactory neuroblastoma. Because both tumors showed identical histological characteristics, it seems difficult to decide which lesion appeared first. However, it should be noted that the ethmoid sinus tumor was found to be larger and more invasive with bone destruction than the maxillary sinus tumor, and that plasma ACTH levels decreased remarkably after initial resection of the ethmoid sinus tumor which contained far greater ACTH contents than those of maxillary sinus tumor. Therefore, it is reasonable to speculate that the olfactory neuroblastoma derived from the ethmoid sinus, which was more aggressive and had increased ACTH synthetic activity, may be the primary lesion which spread to the maxillary sinus by metastasis. An alternative possibility is that the olfactory neuroblastoma developed simultaneously in both the ethmoid and maxillary sinus.

In the present case, failure of high-dose dexamethasone to suppress plasma ACTH and cortisol levels suggests ectopic ACTH syndrome, whereas hyperresponse of ACTH after CRH stimulation suggests Cushing's disease. Sensitivity and specificity of dexamethasone suppression test for the diagnosis of Cushing's disease is $71 \%$ and $100 \%$, respectively [21]. On the other hand, sensitivity and specificity of CRH stimulation test in Cushing's disease is $86 \%$ and $95 \%$, respectively [22]. Thus, conventional endocrine tests could not discriminate between Cushing's disease and ectopic ACTH syndrome as in our case.

It is currently recognized that IPS sampling is the most reliable method to distinguish Cushing's disease from ectopic ACTH syndrome with the diagnostic accuracy close to $100 \%$ [23-25]. However, it should be noted that a step-up $(\mathrm{C} / \mathrm{P}$ ratio $>2)$ of basal plasma ACTH levels by IPS sampling, despite lack of post $\mathrm{CRH}$ data in this case, was misleading as to the source 
of ACTH from the pituitary rather than non-pituitary source. This may be accounted for by the localization of the ethmoid sinus tumor adjacent to the upstream of pituitary venous drainage. Such false positive IPS sampling in the diagnosis of Cushing's disease has only rarely been reported, and include two cases with ectopic ACTH-producing bronchial carcinoid due to possible periodic hormonogenesis [26], and one with ectopic ACTH/CRH-producing neuroendocrine pancreatic tumor [27]. Thus, our case adds to another situation in which aberrant anatomical location of the ectopic ACTH source may cause potential pitfall of IPS sampling in the diagnosis of ACTH-dependent Cushing's syndrome. We recommend selective sampling from cavernous sinus rather than IPS in combi- nation with $\mathrm{CRH}$ stimulation and detailed diagnostic imaging techniques to look for the occult ectopic source of ACTH in the whole body, including parasinus regions of the head.

\section{Acknowledgements}

This study was supported in part by Grants-in-Aids from the Ministry of Education, Science, Sports, Culture, and Technology, and the Ministry of Health, Labor and Welfare, of Japan. We wish to thank Drs M. Tamaki, H. Tomita and M. Yagi, Musashino Red Cross Hospital for their cooperation.

\section{References}

1. Wajchenberg BL, Mendonca BB, Liberman B, Pereira MA, Carneiro PC, Wakamatsu A, Kirschner MA (1994) Ectopic adrenocorticotropin hormone syndrome. Endocr Rev 15: 752-787.

2. Boscaro M, Barzon L, Fallo F, Sonino N (2001) Cushing's syndrome. Lancet 357: 783-791.

3. Raff H, Findling JW (2003) A physiologic approach to diagnosis of Cushing syndrome. Ann Intern Med 130: 980-991.

4. Dulguerov P, Allal AS, Calcaterra TC (2001) Esthesioneuroblastoma: meta-analysis and review. Lancet Oncol 2: 683-696.

5. Arnesen MA, Scheithauer BW, Freeman S (1994) Cushing's syndrome secondary to olfactory neuroblastoma. Ultrastruct Pathol 18: 61-68.

6. Doi M, Imai T, Shichiri M, Tateno T, Fukai N, Ozawa N, Sato R, Teramoto K, Hirata Y (2003) Octoreotidesensitive ectopic ACTH production by islet cell carcinoma with multiple liver metastases. Endocrine $J$ 50: 135-143.

7. Kuriyama G, Takekoshi S, Tojo K, Nakai Y, Kuhar MJ, Osamura RY (2004) Cocaine-and amphethamineregulated transcript peptide in the rat anterior pituitary gland is localized in gonadotrophs and suppresses prolactin release. Endocrinology 145: 2542-2550.

8. Osamura RY, Fine G (1976) Ultrastructure of the esthesioneuroblastoma. Cancer 38: 173-179.

9. Kadish S, Goodman M, Wang CC (1976) Olfactory neuroblastoma. A clinical analysis of 17 cases. Cancer 37: 1571-1576.

10. Broich G, Pagliari A, Ottaviani F (1997) Esthesioneuroblastoma: a general review of the cases published since the discovery of the tumor in 1924. Anticancer Res 17: 2683-2706.
11. Srigley JR, Dayal VS, Gregor RT, Love R, van Nostrand AWP (1983) Hyponatremia secondary to olfactory neuroblastoma. Arch Otolaryngol 109: 559 562 .

12. Osterman J, Calhoun A, Dunham M, Cullim UX Jr, Clark RM, Stewart DD, Scheithauer BW, Zimmerman EA, Defandini R, Zang X, Robinson AG (1986) Chronic syndrome of inappropriate antidiuretic hormone secretion and hypertension in a patient with olfactory neuroblastoma. Arch Intern Med 146: 1731-1735.

13. Cullen MJ, Cusack DA, O'Brien DS, Devlin JB, Kehley A, Lyons TA (1986) Neurosecretion of arginine vasopressin by an olfactory neuroblastoma causing reversible syndrome of antidiuresis. Am J Med 81: 911916.

14. Kenny FM, Stavrides A, Voorhess ML, Klein R (1967) Cushing's syndrome associated with an adrenal neuroblastoma. Am J Dis Child 113: 611-615.

15. Normann T, Havnen J, Mjolnerod O (1971) Cushing's syndrome in an infant associated with neuroblastoma in two ectopic adrenal glands. J Pediatr Surg 6: 169 174.

16. Blatt J, Lee PA, Taylor SR (1988) Neuroblastoma associated with adrenal defects. Pediatrics 82: 790-792.

17. Espinasse-Holder M, Defachelles AS, Weill J, De Keyzer Y, Martin de Lassalle E, Nelken B (2000) Paraneoplastic Cushing syndrome to adrenal neuroblastoma. Med Pediatr Oncology 34: 231-233.

18. Dulguerov P, Calcaterra T (1992) Esthesioneuroblastoma: the UCLA experience 1970-1990. Laryngoscope 102: 843-849.

19. Morita A, Ebersold MJ, Olsen KD (1993) Esthesioneuroblastoma: prognosis and management. Neurosurgery 32: 706-714. 
20. Eden BV, Debo RF, Larner JM, Kelly MD, Levine PA, Stewart FM, Cantrell RW, Constable WC (1994) Esthesioneuroblastoma: long-term outcome and patterns of failure - the University of Virginia experience. Cancer 73: 2556-2562.

21. Duke HL, Nieman LK, Oldfield EH (1994) A comparison of the standard high dose dexamethasone suppression test and the overnight 8-mg dexamethasone suppression test for the differential diagnosis of adrenocorticotropin-dependent Cushing's syndrome. $J$ Clin Endocrinol Metab 78: 418-422.

22. Kaye TB, Crapo L (1990) The Cushing syndrome: An update on diagnostic tests. Ann Intern Med 112: 434444.

23. Oldfield EH, Doppman JL, Nieman LK, Chrousos GP, Miller DL, Katz DA, Cutler GB Jr, Loriaux DL (1991) Petrosal sinus sampling with and without corticotropinreleasing hormone for the differential diagnosis of Cushing's syndrome. N Engl J Med 325: 897-905.

24. Tabarin A, Greselle JF, San-Galli F, Leprat F, Caille
JM, Latapie JL, Roger P (1991) Usefulness of the corticotropin-releasing hormone test during bilateral inferior petrosal sinus sampling for the diagnosis of Cushing's disease. J Clin Endocrinol Metab 73: 53-59.

25. Findling JW, Kohoe ME, Shaker JL, Raff H (1991) Routine inferior petrosal sinus sampling in the differential diagnosis of adrenocorticotropin (ACTH)dependent Cushing's syndrome: early recognition of the occult ectopic ACTH syndrome. J Clin Endocrinol Metab 73: 408-413.

26. Yamamoto Y, Dudley DM, Nippoldt TB, Young WF, Huston JH, Parisi JE (1995) False-positive inferior petrosal sinus sampling in the diagnosis of Cushing's disease. J Neurosurg 83: 1087-1091.

27. Young J, Deneux C, Grino M, Oliver C, Chanson P, Shaison G (1998) Pitfall of petrosal sinus sampling in Cushing's syndrome secondary to ectopic adrenocorticotrpin-corticotropin releasing hormone (ACTH-CRH) secretion. J Clin Endocrinol Metab 83: 305-308. 